\title{
Distinct signal processing properties of two populations of electrosensory neurons exhibiting different levels of spike time variability
}

\author{
Jan Benda* and Jan Grewe
}

Address: Department Biology II, Ludwig-Maximilians-Universität München, 82152 Martinsried, Germany

Email: Jan Benda* - benda@bio.lmu.de

* Corresponding author

from Eighteenth Annual Computational Neuroscience Meeting: CNS*2009

Berlin, Germany. 18-23 July 2009

Published: 13 July 2009

BMC Neuroscience 2009, I0(SuppI I):PI2I doi:10.1I86/I47|-2202-I0-SI-PI2I

This abstract is available from: http://www.biomedcentral.com/I47I-2202/I0/SI/PI2 I

(c) 2009 Benda and Grewe; licensee BioMed Central Ltd.

The role of noise in neural information processing is still a controversial topic and the notion that intrinsic noise inevitably degrades information transmission still dominates the debate. However, in a population of spiking neurons, noise can reduce redundancy and/or control the level of synchrony in response to certain stimulus features [1]. Target neurons may selectively read out synchronous spikes only (coincidence detector) or aspecifically integrate over all input spikes, thereby extracting different aspects of the signal that stimulated the population of input neurons [2]. In this view, the amount of noise in a neural system might be optimally tuned to achieve the required signal processing properties. Experimentally, it is very challenging to prove this hypothesis since it is very difficult, if not impossible, to manipulate the amount of noise independently in many neurons.

Weakly electric fish, however, are an ideal model system for tackling this question. They have two parallel electrosensory systems that share a similar architecture and process similar stimuli but exhibit different response characteristics/variability: the active electrosensory system receiving input from tuberous receptors and the passive one receiving input from ampullary receptors. Interestingly, the baseline discharge of the P-units, the majority of the tuberous receptors, show a much larger variability of their interspike intervals than the one of the ampullary receptors. Thus, they receive input from populations of receptor neurons that discharge regularly (passive system) or irregularly (active system). These two systems are very well suited for a comparative study on the role of noise in both systems. But, whereas the computational properties of the active electrosensory system are quite well studied, the passive system of weakly electric fish still needs to be investigated in detail.

We here present, as a first step, recordings from the receptor neurons of both electrosensory systems. We analyze and compare baseline firing rates, interspike interval distributions and interspike interval correlations to better quantify the variability of the spiking responses (the noise). The response properties to artificial and natural stimuli as expressed by gain functions and coherence, adaptation time constants, spike timing synchrony and other types of correlations within the receptor populations show how this difference in variability influences the signal processing properties of the single neurons as well as of the populations.

\section{Acknowledgements}

Supported by the BMBF through the Bernstein Award to JB.

\section{References}

I. Benda J, Longtin A, Maler L: A synchronization-desynchronization code for natural communication signals. Neuron 2006, 52:347-358.

2. Middleton JW, Longtin A, Benda J, Maler L: Postsynaptic receptive field structure and spike threshold determine encoding of high frequency information via sensitivity to synchronous presynaptic activity. J Neurophysiol 2009 in press. 